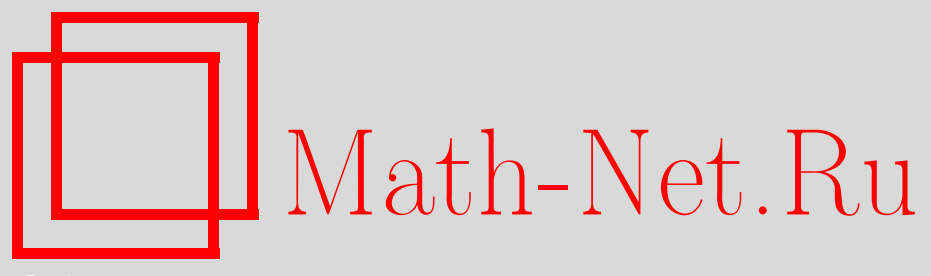

А. Б. Жижченко, А. Д. Изаак, Информационная система Math-Net.Ru. Применение современных технологий в научной работе математика, УМH, 2007, том 62, выпуск $5,107-132$

DOI: https://doi.org/10.4213/rm8147

Использование Общероссийского математического портала Math-Net.Ru подразумевает, что вы прочитали и согласны с пользовательским соглашением http: //www . mathnet.ru/rus/agreement

Параметры загрузки:

IP: 54.197 .217 .227

26 апреля 2023 г., 13:43:50

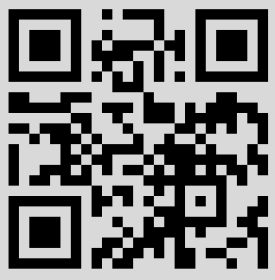




\title{
Информационная система Math-Net.Ru. Применение современных технологий в научной работе математика
}

\begin{abstract}
А. Б. Жижченко, А. Д. Изаак
Работа посвящена описанию информационной системы Math-Net.Ru общероссийского математического портала, предоставляющего российским и зарубежным математикам различные возможности в поиске необходимой в научной работе информации (http://www.mathnet.ru/).

Наиболее интересным разделом портала является раздел "Журналы", который связывает российские периодические и продолжающиеся издания в области математических наук в единую систему.

Описана структура портала, его различные возможности и имеющиеся средства поиска необходимой информации.

Дан обзор аналогичных российских и зарубежных систем.

Работа рассчитана на широкий круг математиков, готовых использовать новые информационные технологии в своей научной работе. Опущены технические подробности реализации системы, основной упор сделан на описание ее возможностей с точки зрения конечного пользователя.

Библиография: 21 название.
\end{abstract}

\section{СоДЕРЖАНИЕ}

1. Введение............................................... 108

2. Структура портала Math-Net.Ru .......................... 110

2.1. Журналы ........................................ 110

2.2. Публикации ..................................... 110

2.2.1. Аннотация .................................. 110

2.2.2. Список цитируемой литературы ................. 111

2.2.3. Ссылки на Google Scholar ........................ 112

2.2.4. Ссылки на реферативные базы данных .............. 113

Журнал впервые публикует два обзора, посвященные информационным системам в области математики, которые разработаны в институтах РАН в Москве и Новосибирске. Редколлегия надеется, что они заинтересуют широкий круг читателей. - Прим. ред.

Работа выполнена при поддержке программы фундаментальных исследований Президиума РАН "Разработка фундаментальных основ создания научной распределенной информационно-вычислительной среды на основе технологий GRID" и программы фундаментальных исследований ОМН РАН "Математические и алгоритмические проблемы информационных систем нового поколения".

(C) А.Б. ЖиЖченко, А. Д. ИзААК, 2007 
2.3. Персоналии...................................... 113

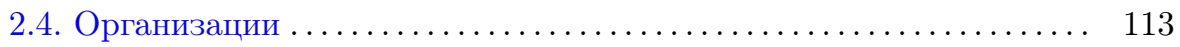

2.5. Личный кабинет..................................... 114

2.6. Закрытая часть портала . . . . . . . . . . . . . . . . . . 116

2.6.1. Заполнение баз данных портала на закрытом сайте ...... 116

2.6.2. Электронный документооборот редакций журналов....... 116

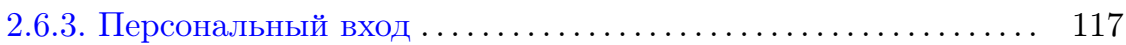

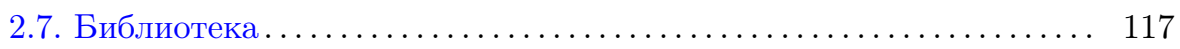

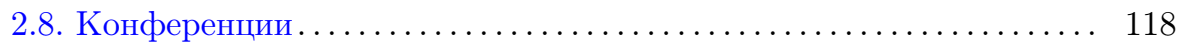

3. Поиск информации на портале Math-Net.Ru .................. 118

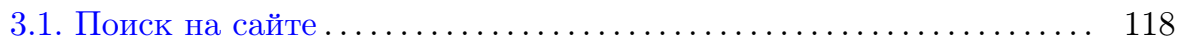

3.2. Поиск персоналий и организаций ..................... 119

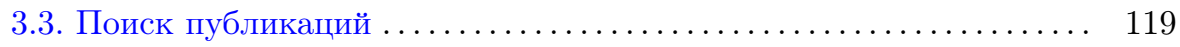

4. Система дифференцированного доступа к ресурсам портала........ 121

4.1. Доступ к полным текстам статей ....................... 121

4.2. Регистрация на портале . . . . . . . . . . . . . . . . . 123

5. Обзор аналогичных российских и зарубежных информационных ресурсов в области математических наук .................. 123

5.1. Сайты российских математических журналов ............. 123

5.2. Информационная система MathTree .................... 123

5.3. Сайты зарубежных издательств .................... 124

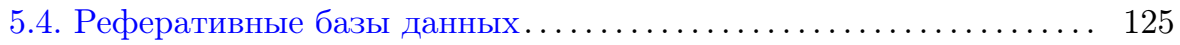

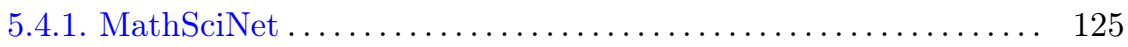

5.4 .2 . Zentralblatt MATH ........................... 128

6. Перспективы развития портала Math-Net.Ru ................ 128

6.1. Подписка на текущие выпуски электронных версий изданий.... 128

6.2. Создание реферативной базы данных................. 129

6.3. Расширение списка участвующих в проекте журналов ......... 129

6.4. Единая база данных цитируемой литературы ............... 130

6.5. Сотрудничество с ассоциацией CrossRef .................. 130

6.6. Видеотека ................................... 130

Список цитируемых Интернет-ресурсов ....................... 131

\section{1. Введение}

В последнее время бурно развиваются информационные технологии, ориентированные на работу с большими объемами специализированной информации. K числу таких технологий относятся электронные информационные технологии и Интернет-технологии как технологии корпоративной работы с такого рода информацией.

В сфере науки роль современных технологий особенно велика в связи с существующим информационным голодом, вызванным падением объема подписки научных библиотек, существенным сокращением числа получаемых библиотеками изданий, уменьшением числа издаваемых русскоязычных книг и журна- 
лов и падением их тиражей, а также недостаточным количеством информации об уже имеющихся работах. Не только развитие, но и поддержка научных исследований на должном уровне немыслима без оперативного обмена информацией на уровне, соответствующем ее объему.

Единственным выходом из сложившейся ситуации является создание и использование сетевых информационных ресурсов и распространение в электронном виде (в первую очередь через Интернет) как уже имеющихся (преимущественно только в бумажном печатном виде), так и новых публикаций. Внедрение современных компьютерных и телекоммуникационных технологий, и особенно информационных технологий, призвано качественно изменить организацию информационных ресурсов, их хранение и обеспечение доступа к ним.

Одному из таких ресурсов - Общероссийскому математическому порталу "Math-Net.Ru" [1] - и посвящена настоящая работа. Math-Net.Ru - это современная информационная система, призванная обеспечить доступ российского и международного математического сообщества к российским источникам информации через всемирную сеть Интернет.

Оперативный доступ к информации о научных организациях, математиках и, в первую очередь, к научным публикациям является необходимым условием научной деятельности.

Ключевым компонентом портала стал раздел "Журналы", собравший ведущие российские математические журналы в единую систему. В разделе "Журналы" представлены как текущие выпуски периодических изданий, участвующих в проекте, так и их архивы (включая полные тексты статей). В настоящий момент здесь представлены семнадцать изданий. Разрабатываемое программное обеспечение позволяет легко ориентироваться в потоке научной информации и отбирать публикации по интересующей тематике.

Закрытая часть портала дает возможность редакциям журналов наладить электронный документооборот, связанный с работой по подготовке статей к печати.

Раздел “Личный кабинет" портала Math-Net.Ru содержит ряд сервисов, позволяющих облегчить работу математиков по подготовке своих рукописей.

В разделе "Библиотека" находятся книжные каталоги и сводный журнальный каталог библиотек Математического института им. В.А. Стеклова РАН, Петербургского отделения Математического института им. В. А. Стеклова РАН и Вычислительного центра им. А. А. Дородницына РАН, а также база данных библиографических описаний статей в российских математических журналах.

Благодаря тому, что бо́льшая часть информации представлена как на русском, так и на английском языке, Общероссийский математический портал вышел за рамки российской аудитории и стал частью международной научной информационной системы.

Общероссийский математический портал Math-Net.Ru создан и развивается Математическим институтом им. В. А. Стеклова РАН совместно с Отделением математических наук РАН в рамках проектов "Математические и алгоритмические проблемы создания и сопровождения информационных систем в области математических наук" программы фундаментальных исследований Президиума РАН "Разработка фундаментальных основ создания научной распределенной информационно-вычислительной среды на основе технологий GRID" 
и "Развитие российской информационной системы в области математических наук" программы фундаментальных исследований ОМН РАН "Математические и алгоритмические проблемы информационных систем нового поколения".

\section{2. Структура портала Math-Net.Ru}

2.1. Журналы. На стартовой странице каждого журнала представлена краткая информация о журнале и состав редколлегии. Кликнув на фамилию члена редколлегии, можно перейти на его персональную страницу на портале Math-Net.Ru (см. п. 2.3). Кроме того, здесь представлены "Правила для авторов" и "Историческая справка".

Перейти на страницу публикации можно несколькими способами:

1. В “Архиве” выбрать конкретный выпуск журнала и, перейдя на страницу содержания этого выпуска, кликнуть на название нужной статьи.

2. Непосредственно на стартовой странице журнала в окне быстрого поиска набрать год, том, выпуск и номер страницы и сразу перейти на соответствующую статью.

3. Открыть окно поиска публикаций и попытаться найти статью по множеству различных параметров (см. п. 3.3).

Некоторые редакции также поддерживают рубрику "Скоро в журнале", где можно посмотреть список статей, которые будут опубликованы в ближайших выпусках журнала. Заметим, что уже на этой стадии статьям присваиваются уникальные идентификационные номера. Тем самым, скажем, автор будущей публикации может поместить ссылку на свою статью в Интернете и она не изменится после того, как статья приобретет статус опубликованной и из рубрики "Скоро в журнале" переместится в соответствующий выпуск.

Например, адрес этой статьи в Интернете - http://mi .mathnet.ru/umn8147 (или http://mi.mathnet.ru/eng/umn8147 для страницы с английским интерфейсом), где "Mi umn8147" - идентификационный номер статьи. Имеется также и альтернативная короткая запись адреса страницы уже опубликованных статей: http://mi.mathnet.ru/jjj/vvv/iii/ppp, где jjj - буквенный код журнала (с которого начинаются все идентификационные номера), vvv - номер соответствующего тома, iіi - номер выпуска, ppp - номер первой страницы статьи. Таким образом, еще один вариант записи адреса настоящей статьи http://mi.mathnet.ru/umn/62/5/107 (для страницы с английским интерфейcom - http://mi.mathnet.ru/eng/umn/62/5/107).

2.2. Публикации. Страница публикации представляет собой набор стандартных метаданных: название и авторы статьи, аннотация, УДК, ключевые слова, дата поступления статьи в редакцию и т. п. Кликнув на автора статьи или место его работы/учебы, можно попасть на соответствующие страницы портала из разделов "Персоналии" и "Организации".

2.2.1. Аннотация. Аннотация к статье изначально видна в текстовом формате, формулы при этом записаны командами $\mathrm{T}_{\mathrm{E}}$ 'а. Для аннотаций с небольшим количеством формул большинству читателей этого представления вполне достаточно. Однако при большом количестве формул чтение текста становится затруднительным. В этом случае есть возможность получить текст аннотации в одном из двух альтернативных форматов - pdf или "html с картинками". 
Вообще, приемлемое представление формул в сети Интернет является давней проблемой. Дело в том, что стандартные возможности языка html, используемого при создании Интернет-страниц, в части отображения математических формул очень ограничены.

Pdf-формат дает результат, ничем не отличающийся по качеству от полиграфического, однако сам pdf-файл получается несколько громоздким, а его отображение на экране компьютера требует установки специальной программыпросмотрщика (Adobe Reader, Adobe Acrobat и др.).

Существуют и другие способы решения обсуждаемой проблемы: представление аннотации в виде одной большой картинки, использование языка математической разметки MathML (Mathematical Markup Language) [2] и др.

Нам же представляется оптимальным решением представление аннотации в виде стандартного html-файла с маленькими картинками вместо формул "html c картинками". Для автоматической конвертации исходного текста аннотации, хранящегося в базе данных в формате $\mathrm{T}_{\mathrm{E}}$, в рамках описываемого проекта был создан модуль latex $2 \mathrm{html}$ - существенно переработанный стандартный конвертор IATEX2HTML [3], который сам по себе не позволяет получать безупречное отображение математических текстов.

Проведенная работа позволила радикально улучшить качество графического отображения самих формул и столь же радикально улучшить их позиционирование в тексте. Кроме того, была сделана полноценная русификация этой программы с качественной поддержкой основных кодировок.

Для ознакомления российского и мирового математического сообщества с результатами разработок создан сайт "Конвертирование IATEX в html" [4], содержащий все дополнения и изменения к официальной версии IATEX2HTML. Ha нем пользователи имеют возможность зарегистрироваться и получить консультацию, а также опубликовать свои замечания, дополнения или предложения.

Отметим, что модуль latex $2 \mathrm{html}$ также используется на сайтах Математического института им. В. А. Стеклова РАН [5] (раздел "Семинары") и Московского математического общества [6] (раздел “Заседания ММО”). Эти сайты разрабатывались и функционируют при частичной поддержке проекта Math-Net.Ru.

2.2.2. Список цитируемой литературы. Вернемся к странице публикации на портале Math-Net.Ru. Kроме основных данных о статье здесь представлен как отдельный ресурс список цитируемой литературы.

Аналогично аннотации, здесь также предлагаются две формы представления - pdf-файл и html с картинками. Основной задачей было не столько решить проблему приемлемого представления немногочисленных формул, встречающихся в названиях цитируемых публикаций (эта задача решается аналогично предыдущей), сколько хранить каждый элемент списка в четко структурированном виде. Скажем, если цитируется статья в журнале, необходимо отделить авторов статьи, ее заголовок, название журнала, год, том, выпуск, первую и последнюю страницы и т. п. Это позволяет представлять списки литературы в различных форматах.

Кроме того, появляется замечательная возможность увидеть список публикаций из базы данных портала, которые цитируют данную статью. Это было в принципе невозможно в “доэлектронную" эпоху. Например, статья 
М. С. Аграновича и М. И. Вишика "Эллиптические задачи с параметром и параболические задачи общего вида", УМН, 19:3 (1964), 53-161 присутствует в 61 списке цитируемой литературы; статья Б. А. Дубровина, В. Б. Матвеева и С. П. Новикова "Нелинейные уравнения типа Кортевега-де Фриза, конечнозонные линейные операторы и абелевы многообразия”, УМН, 31:1 (1976), 55-136 2 в 55 списках. Заметим, что в настоящий момент далеко не ко всем статьям в базе данных "Журналы" приложен структурированный список литературы, поэтому числа в приведенных примерах будут со временем расти.

Если публикация - элемент списка - присутствует в базе данных “Журналы" портала Math-Net.Ru, в одной из реферативных баз данных (MathSciNet, Zentralblatt MATH, ADS NASA, см. п. 2.5) или имеет DOI (см. п. 6.5), рядом с публикацией размещаются иконки с логотипами, содержащие ссылки на соответствующие сайты с информацией об этой публикации.

В рамках проекта разработан модуль MiRef, предназначенный для автоматической расстановки этих ссылок. Модуль MiRef используется и в разделе "Личный кабинет" при работе посетителей портала со списками литературы (см. п. 2.5).

Немаловажной также является возможность представления структурированных списков литературы для их передачи во внешние Интернет-ресурсы. В настоящее время такое взаимодействие осуществляется с двумя ресурсами: порталом Отделения математических наук РАН [7] и замечательным разделом международной поисковой системы Google - "Google Scholar" [8], предназначенным для эффективного поиска научных публикаций в сети Интернет.

2.2.3. Ссылки на Google Scholar. Налаженное сотрудничество с представителями Google позволило регулярно обновлять базу данных Google Scholar информацией как о самих публикациях, собранных на портале Math-Net.Ru, так и о списках цитированной в этих статьях литературы. Результат этого сотрудничества - корректное отображение результатов поиска публикаций пользователями Google Scholar, причем как на английском, так и на русском языках.

Взаимодействие с Google позволило на странице каждой публикации разместить по две пары ссылок на страницы Google Scholar.

"Citing articles on Google Scholar: Russian citations, English citations" - ссылки на списки публикаций, цитирующих данную. На странице публикации на портале Math-Net.Ru автоматически появляется список статей, цитирующих эту публикацию. Но список этот включает в себя только статьи из базы данных портала. Здесь же мы можем увидеть куда более полный список цитирующих ее всевозможных статей, книг, электронных препринтов и других публикаций на разных языках, опубликованных как в российских, так и в зарубежных издательствах.

"Related articles on Google Scholar: Russian citations, English citations" - ссылки на списки публикаций, "близких" данной. Точного описания того, что разработчики понимают под этой “близостью”, на сайте Google Scholar нет. Тем не менее, списки получаются любопытными и, как нам представляется, полезными для поиска схожих по тематике работ.

\footnotetext{
${ }^{1}$ http: //mi.mathnet.ru/umn6210

${ }^{2}$ http://mi .mathnet.ru/umn3642
} 
2.2.4. Ссылки на реферативные базы данных. Подавляющее большинство публикаций из базы данных “Журналы" портала Math-Net.Ru peферируется ведущими международными реферативными журналами. На страницах таких публикаций можно найти ссылки на соответствующие рефераты в информационных системах MathSciNet [9] и Zentralblatt MATH [10] (подробнее об этих системах см. п. 5.4).

2.3. Персоналии. В базе данных "Персоналии" портала Math-Net.Ru coбрана информация о российских и зарубежных математиках. В первую очередь, это авторы публикаций из базы данных "Журналы". Но не только. Любой посетитель портала может создать здесь собственную персональную страницу, заполнив небольшую регистрационную форму. Для этого достаточно иметь хотя бы одну научную публикацию (совсем не обязательно в издании, представленном на портале).

В момент написания настоящей статьи база данных "Персоналии" насчитывала более 13000 записей. Полнота и актуальность собранной здесь информации резко отличается у разных персон. О большинстве авторов статей, вышедших несколько десятков лет тому назад, не известно ничего, кроме их фамилий и инициалов. Не представляется возможным также поддерживать в актуальном состоянии такую информацию, как номер телефона или последнее место работы. Однако если математик сам выражает заинтересованность в том, чтобы информация о нем была полной и актуальной, он может в любой момент отредактировать и дополнить ее, предварительно зарегистрировавшись на сайте (см. п. 4.2).

Заполнив все поля базы данных - от контактной информации до основных тем научной работы, научной биографии и списка основных публикаций, пользователь получает собственную двуязычную персональную страницу в сети Интернет.

Кроме списка основных публикаций, который сам автор формирует по своему усмотрению, на странице персоналии автоматически создается список его статей, присутствующих в базе данных портала. Эти статьи разделены на две группы - научные статьи и статьи, посвященные различным аспектам математической жизни - юбилеям, конференциям и т. п.

Скажем, “лидерами" по количеству научных публикаций в журнале "Успехи математических наук" за последние 50 лет являются О.А. Олейник (53 статьи), С. П. Новиков (36 статей), В. М. Бухштабер (35 статей), И. М. Гельфанд (33 статьи), Я. Г. Синай (32 статьи).

2.4. Организации. База данных "Организации” портала Math-Net.Ru coдержит информацию об организациях математического профиля. В первую очередь, это российские и зарубежные организации, в которых работают или учатся авторы публикаций, представленных на портале.

Кроме информации о самой организации, доступен список персоналий, "имеющих отношение к данной организации". Поскольку практически невозможно отследить, в какой момент какой математик меняет свое место работы или учебы, на портале Math-Net.Ru к каждой персоналии "привязано", как правило, несколько организаций, в том числе те организации, которые они как авторы указывали в своих публикациях в разные годы. Тем самым нельзя думать, что 
список персоналий, доступный на странице организации, составлен только из ее нынешних сотрудников. Здесь есть и люди, работавшие или обучавшиеся в ней в прошлом.

Несмотря на то что на портале присутствуют только российские издания, доля зарубежных организаций от их общего числа довольно высока - около $40 \%$. Это объясняется, во-первых, большой популярностью российских изданий среди математиков из стран бывшего Советского Союза. Во-вторых, публикуется довольно много совместных работ российских и зарубежных математиков. И, кроме того, многие уехавшие на Запад российские математики по-прежнему публикуют свои работы в отечественных журналах.

Безусловно, хотелось бы иметь максимально полную и актуальную информацию о ведущих российских математических организациях (академических институтах, математических факультетах университетов и т.д.) и сотрудниках этих организаций. Однако здесь невозможно обойтись силами маленького коллектива разработчиков портала, а необходимо применить так называемый "административный ресурс".

Давно ведется речь о подготовке специального распоряжения Президиума PAН, предписывающего научным организациям Академии наук представлять сведения о своих организациях, включая информацию о сотрудниках, и обязывающего эти организации следить за своевременным обновлением этой информации.

2.5. Личный кабинет. Раздел "Личный кабинет" задуман как набор полезных инструментов в помощь математику. В настоящий момент такой инструмент один - модуль MiRef, предназначенный для работы со списками цитируемой литературы.

Как правильно оформить список цитируемой в статье литературы? Имеется соответствующий ГОСТ, однако все большее количество российских изданий перестает на него ориентироваться. Это происходит по ряду причин, в первую очередь, на наш взгляд, из-за резкого отличия этих стандартов от стандартов, принятых в зарубежных издательствах.

B рамках проекта Math-Net.Ru разработан пакет amsbib, предназначенный для набора библиографии в LATEX2е с использованием специальных команд. Использование этих команд позволяет избежать явной разметки списка литературы (явного выделения различных элементов путем использования различных шрифтов, пунктуации, скобок и т. п.) и неизбежной при этом переделки файлов при подготовке рукописей к печати, а также позволяет автоматически создавать гиперссылки в списке литературы на различные базы данных публикаций.

Стиль оформления литературы пакета amsbib соответствует стилю, принятому в ведущих журналах Отделения математических наук РАН.

Модуль MiRef помогает создать список литературы, не задумываясь о стиле. Достаточно в интерактивном режиме выбрать тип публикации и ввести в соответствующие поля информацию о ней. В результате формируется структурированный список литературы, набранный командами пакета amsbib.

Затем можно запустить процесс автоматического поиска каждой публикации из списка в различных базах данных. В настоящий момент это четыре 
базы данных. Собственно база данных публикаций, представленных на портале Math-Net.Ru, а также три международные реферативные базы данных: MathSciNet Американского математического общества [9], Zentralblatt MATH Европейского математического общества [10] и ADS NASA [11] - Астрофизическая информационная система, финансируемая Национальным агентством по аэронавтике и исследованию космического пространства США (NASA).

Получившийся список литературы можно вставить в $\mathrm{T}_{\mathrm{E}} \mathrm{X}$ файл статьи, подключив в преамбуле пакет amsbib, скачав предварительно файл amsbib.sty. А можно просто кликнуть мышкой на кнопку "Открыть PDF файл" и сразу получить pdf-файл со списком литературы и работающими гиперссылками на базы данных публикаций.

Приведем пример работы с модулем MiRef. Введем в соответствующую форму данные о статье, опубликованной в "Успехах математических наук" в 1989 году (см. рис. 1).

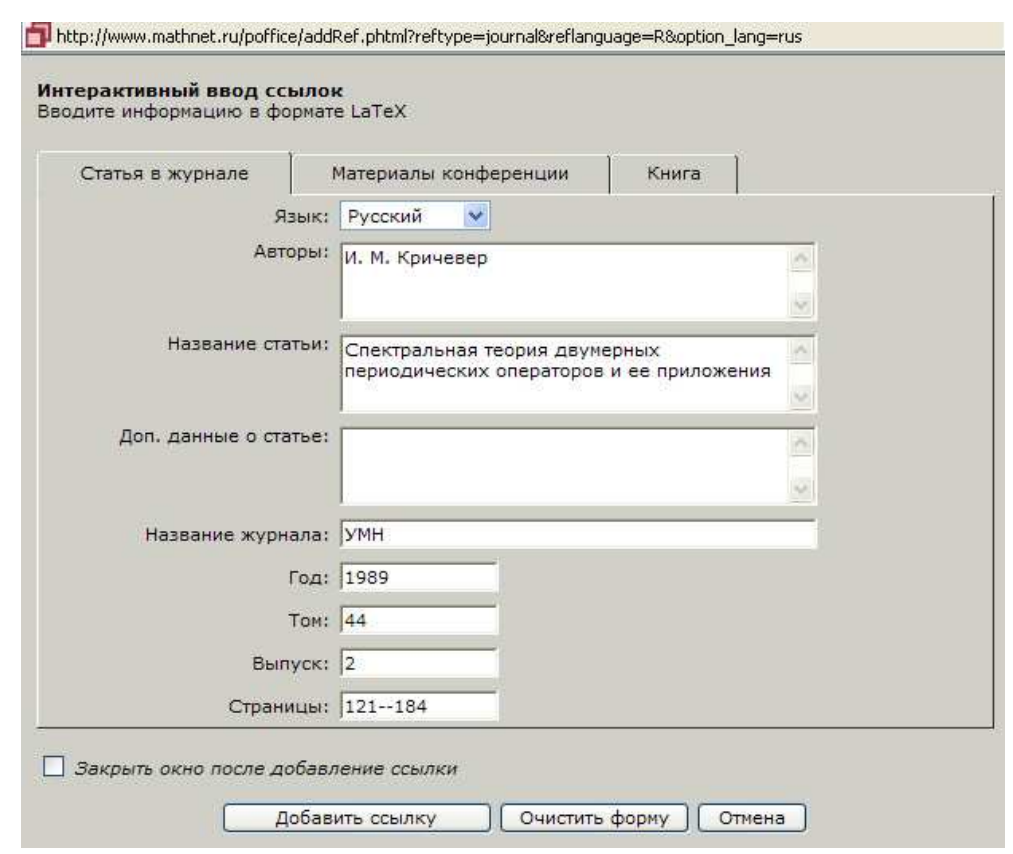

Рис. 1

Кликнув на кнопку “Добавить ссылку", в окне "Работа со списком литературы" получим представление этой статьи командами пакета amsbib:

$\backslash$ begin $\{$ thebibliography $\{9\}$

$\backslash$ RBibitem\{1\}

by И. М. Кричевер

$\backslash$ paper Спектральная теория двумерных периодических операторов

и ее приложения

$\backslash$ jour $\mathrm{YMH}$

yy 1989

|vol 44

\issue 2 
$\backslash$ pages 121--184

$\backslash$ end $\{$ thebibliography\}

Кликнув на кнопку "Создать ссылки", затем два раза "ОК”, после строки "\pages 121--184" появятся три новые:

...

$\backslash$ pages 121--184

$\backslash$ mathnet $\{\mathrm{rm} 2275\}$

$\backslash$ mathscinet $\{998363\}$

$\backslash$ zmath\{0699.35188\}

\end\{thebibliography\} }

Кликнув на кнопку “Открыть PDF файл”, получим pdf-файл с работающими гиперссылками:

\section{Список литературы}

[1] И. М. Кричевер, "Спектральная теория двумерных периодических операторов и ее приложения", УМH, 44:2 (1989), 121-184 Mi rm2275, MR 998363, Zbl 0699.35188.

Заметим, что зарегистрированные пользователи (см. п. 4.2) имеют возможность сохранять файлы со своими списками литературы, а также загружать файлы, сохраненные ранее на сервере Math-Net.Ru.

\section{6. Закрытая часть портала.}

2.6.1. Заполнение баз данных портала на закрытом сайте. Ввод информации в базы данных портала осуществляется через закрытый сайт в сети Интернет https://edit.math-net.mi.ras.ru. Для работы оператора баз данных не требуется ничего, кроме персонального компьютера, подключенного к Интернету, на котором установлен обычный браузер, скажем Internet Explorer. Попасть на сайт можно только зная соответствующий пароль. При этом каждый сотрудник имеет собственный уровень доступа к просмотру и редактированию информации.

На рис. 2 приведен пример того, как выглядит "карточка" публикации, которую необходимо заполнить, чтобы информация об этой публикации попала в соответствующую базу данных.

2.6.2. Электронный документооборот редакций журналов. Кроме ввода информации об уже опубликованных статьях, имеется возможность наладить электронный документооборот в редакциях журналов, участвующих в проекте, отслеживая все этапы поступивших в редакцию статей: рецензирование, рассмотрение на редколлегии, отправку на доработку авторам и т. д. На рис. 3 приведен пример работы со статьей, поступившей в редакцию журнала "Известия РАН. Серия математическая", которая была в результате отклонена.

Система также позволяет автоматически выдавать различные списки статей, находящихся в работе редакции, отбирая и группируя их по различным параметрам: дате поступления, ответственному члену редколлегии, определенному статусу статьи и т. д. Автоматически формируются и ведомости на выплату авторского гонорара. 


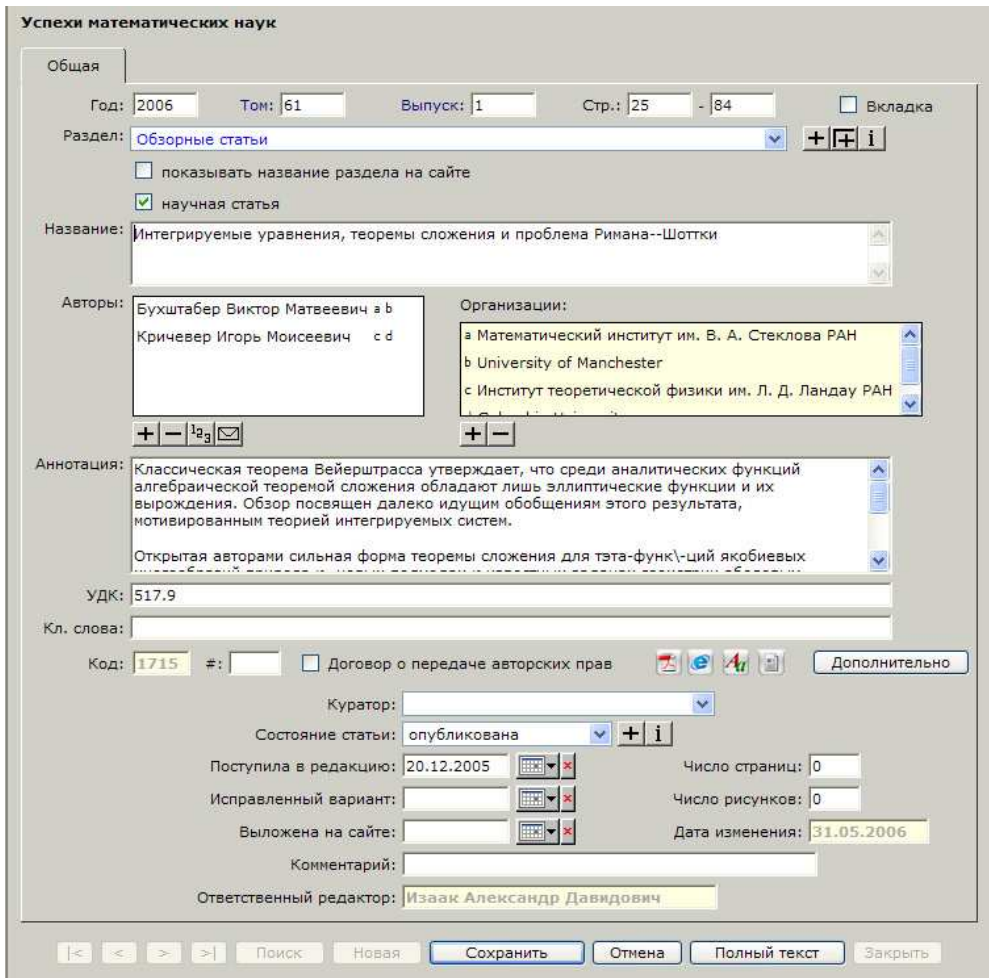

Рис. 2

2.6.3. Персональный вход. В предыдущих двух пунктах описывалась работа с базами данных портала на закрытом сайте. Однако и на "основном" сайте портала Math-Net.Ru есть "закрытая" часть - так называемый "Персональный вход". Через него авторы могут подать в электронном виде рукопись новой статьи в журнал и отслеживать статус уже поданных ранее статей. А члены редколлегий, рецензенты и прочие участники процесса могут работать со статьями, к которым они имеют то или иное отношение: получать на отзыв файлы статей, передавать написанные рецензии и т. д. и т. п.

K сожалению, далеко не все редакции журналов начали использовать описываемую систему электронного документооборота. Сказывается инерционность и консерватизм сотрудников редакций и редколлегий журналов. В настоящее время активно используют возможности системы четыре журнала Отделения математических наук РАН - "Известия РАН. Серия математическая", "Математические заметки", "Математический сборник" и "Успехи математических наук".

2.7. Библиотека. Раздел "Библиотека" содержит книжные каталоги и сводный журнальный каталог библиотек Математического института им. В.А. Стеклова РАН, Петербургского отделения Математического института им. В.А. Стеклова РАН и Вычислительного центра им. А. А. Дородницына PAH, а также базу данных библиографических описаний статей 


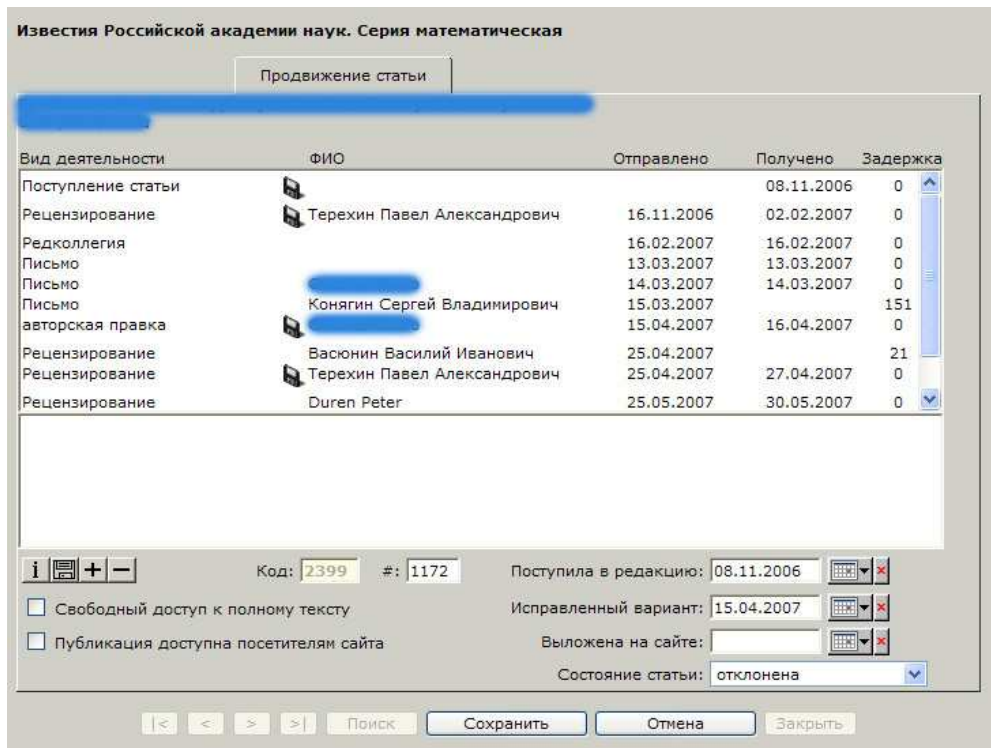

Рис. 3

в 42 отечественных математических журналах, содержащую более 85 тысяч записей.

Инициатором и организатором работ по созданию и наполнению этих каталогов выступает Библиотека Математического института им. В. А. Стеклова PAH.

2.8. Конференции. Раздел "Конференции" полностью соответствует своему названию. Он включает расписание и краткую информацию о предстоящих математических конференциях в стране, а также архив уже состоявшихся конференций.

Любой посетитель портала Math-Net.Ru может зарегистрировать новую конференцию, заполнив соответствующую регистрационную форму.

\section{3. Поиск информации на портале Math-Net.Ru}

Одним из главнейших преимуществ современной информационной системы перед простым набором файлов с журнальными статьями или, тем более, перед набором печатных выпусков журналов на полке научной библиотеки является возможность оперативного поиска необходимой информации по различным наборам параметров.

3.1. Поиск на сайте. Самым простым является "Поиск по сайту", доступный уже на главной странице портала. Например, введя в поле поиска "Стеклов", получим ссылки на две организации, в названия которых входит эта фамилия, ссылку на персональную страницу Владимира Андреевича Стеклова и ссылки на пару десятков публикаций, в названиях или в аннотациях к которым упоминается это слово. 
3.2. Поиск персоналий и организаций. Перейдя в раздел "Персоналии", мы попадаем на страницу их поиска. Самый простой способ найти нужную персоналию - заполнить поле "Фамилия" и нажать кнопку "Поиск". Например, введя в это поле слово "Стеклов", получим одну ссылку на персональную страницу В. А. Стеклова. А если наберем слово "Иванов", получим около пятидесяти ссылок на персональные страницы различных Ивановых.

Можно придумать и более нетривиальные варианты запроса. Например, если ввести то же слово “Стеклов" в поле “Организация", получим список около 450 персоналий, имевших в разное время отношение к Математическому институту им. В.А. Стеклова или Санкт-Петербургскому отделению Математического института им. В. А. Стеклова.

Если с написанием фамилий российских ученых на русском языке проблем обычно не возникает, то с написанием этих же фамилий по-английски уже не все так просто. Существует масса различных способов так называемого транслитерирования фамилий, т. е. способов их записи латинскими буквами. Приведем пример различных способов транслитерирования фамилии "Чебышев" в реферативной базе данных MathSciNet: Chebyshev, Tchebychef, Tchebycheff, Tschebycheff, Tschebyscheff, Čebyšev.

В базе данных "Персоналии" портала Math-Net.Ru принято следующее соглашение. Как правило, фамилии записываются по правилам транслитерации, принятым в настоящее время Американским математическим обществом (близким к стандарту ISO-R9-1968). Однако если автор по той или иной причине пишет свою фамилию иначе или фамилия имеет иностранное происхождение, то система "синонимов" позволяет найти необходимую персоналию независимо от способа ее написания латиницей.

Например, чтобы найти ссылку на страницу В. М. Бухштабера, можно на английской странице поиска персоналий портала в поле "Last name" (или на русской странице поиска в поле “Фамилия", выбрав язык поиска “Английский”) набрать "Bukhshtaber" (запись фамилии согласно принятым на портале правилам транслитерирования) или "Buchstaber" ("правильная" запись фамилии). В результате в обоих случаях получим необходимый результат - ссылку на страницу "Buchstaber Viktor Matveevich [Bukhshtaber Viktor Matveevich]".

Аналогично устроен и поиск организаций. Отметим только, что информация о российских и большинстве организаций из стран бывшего Советского Союза доступна как на русском, так и на английском языках. Информация об остальных зарубежных организациях доступна, как правило, только на английском языке.

3.3. Поиск публикаций. Поиск публикаций можно осуществлять как внутри определенного издания, так и по всем изданиям одновременно. Вести его можно по нескольким параметрам. Приведем несколько характерных примеров поисковых запросов.

Пример 1. В поле "ЖКурнал" поисковой формы выберем "Все журналы", а в поле "Авторы" введем фамилию автора интересующих нас работ. Например, набрав "Новиков", получим список из более 150 публикаций (авторов по фамилии "Новиков" или "Новикова" в базе данных "Персоналии" более двадцати!). Можно набрать несколько фамилий, разделенных пробелом или запятой. Например, набрав “Дынников Новиков”, получим три совместные работы 
И. А. Дынникова и С. П. Новикова. Можно набирать фамилии авторов не целиком. Набрав “дын нов", получим те же три работы из предыдущего примера плюс работу, авторы которой - Е. Б. Дынкин и С. П. Новиков.

Заметим, что если мы просто хотим найти работы вполне конкретного автора, правильней поиск начать с раздела "Персоналии", выбрать там нужного автора и зайти на его персональную страницу, на которой, кроме всего прочего, сразу будет виден список всех его публикаций, представленных на портале Math-Net.Ru.

ПримеР 2. Поиск будем вести среди статей из "Успехов математических наук". В поле "Ключевые слова" введем слово "Меньшов". Если выбрать параметр "в названии", найдется несколько публикаций, в названии которых встречается фамилия Меньшов: "Дмитрий Евгеньевич Меньшов (к 100-летию со дня рождения)", "О развитии результатов Д.Е. Меньшова по теории ортогональных рядов" П. Л. Ульянова, "Работы Д. Е. Меньшова по теории аналитических функций и современное состояние теории моногенности" Е. П. Долженко и т. д.

Если выбрать параметр “в названии и аннотации”, найдется уже больше публикаций, например, статья П. Л. Ульянова "О работах Н. Н. Лузина по метрической теории функций”. Фамилия Д. Е. Меньшова здесь упоминается в аннотации к статье.

Если же выбрать параметр “в полном тексте", найденных публикаций будет в несколько раз больше. Например, будет найден некролог Евгения Михайловича Никишина, поскольку упоминание о Д.Е. Меньшове есть в самом тексте этой статьи: “Студентом 2-го курса, увлекшись математикой, Евгений Михайлович посещает на механико-математическом факультете МГУ семинар Д. Е. Меньшова и П. Л. Ульянова по теории ортогональных и тригонометрических рядов и вскоре под руководством П. Л. Ульянова начинает самостоятельную научную работу".

Поиск по ключевым словам из полных текстов статей возможен, даже если доступ к самим полным текстам закрыт (см. п. 4.1).

Заметим также, что поиск по ключевым словам доступен и в большинстве pdf-файлов полных текстов статей, хранящихся на портале. В том числе и в тех файлах, которые были получены в результате сканирования печатных выпусков журналов (текстовая "подложка" добавляется к отсканированным "картинкам" страниц с помощью программы ABBYY FineReader).

ПримеР 3. Приведем пример более хитрого запроса. Допустим, мы хотим найти все публикации, выполненные сотрудниками Института математики им. С. Л. Соболева СО РАН в 2006 году.

Поиск будем вести по всем изданиям, представленным в базе данных "Журналы". В поле "Организация" введем слово "Соболев" и выберем период "с 2006 по 2006". Нажмем на кнопку "Искать" и получим более 90 статей в различных журналах. Заодно будут найдены и несколько статей сотрудников Омского филиала Института математики.

Заметим, что в последнем случае статьи попадут в искомый список, только если автор указал в публикации в качестве места своей работы/учебы соответствующую организацию. 
ПримеР 4. Можно искать ссылки на различные публикации из списков цитированной литературы к статьям из базы данных "Журналы". Введем "Гантмахер Теория матриц" в поле "Ключевые слова" и выберем параметр "в полном тексте". Результат такого запроса - около 100 публикаций, цитирующих книгу Ф.Р. Гантмахера "Теория матриц". Например, будет найдена статья А. В. Гулина и А. А. Самарского "О некоторых результатах и проблемах теории устойчивости разностных схем", Матем. сб., 1976, 99(141):3, 299-330; в списке цитируемой литературы которой действительно есть запись

[29] Ф.Р. Гантмахер, Теория матрии, изд-во "Наука", Москва, 1967.

\section{4. Система дифференцированного доступа к ресурсам портала}

4.1. Доступ к полным текстам статей. Доступ к собранной в архивах портала Math-Net.Ru информации свободный, за исключением доступа к файлам с полными текстами статей. В таблице 1 приведены уровни доступа к каждому изданию, представленному на портале.

Как видно из таблицы 1 , доступ к полным текстам статей открыт полностью или с небольшой задержкой для всех изданий, кроме журналов, выпускаемых Издательством "Наука". 3 В течение длительного времени нами предпринимаются попытки договориться с издательством хоть о каком-нибудь соглашении в этом направлении. Предлагались различные варианты - от полностью открытого доступа до дифференцированного доступа определенным группам посетителей портала: только для сотрудников российских академических институтов, только для подписчиков печатных версий журналов и т. п. Пока, к сожалению, результат нулевой. Файлы статей из этих журналов остаются недоступными для всех.

Ситуация становится просто комичной. Сколько раз мы получали письма от наших коллег, находящихся в заграничных командировках, в которых они с восторгом писали о прекрасной возможности пользоваться там электронными архивами английских (!) версий "наших" журналов. Или, скажем, в Математическом институте им. В. А. Стеклова РАН открыт доступ к полным текстам статей большинства изданий, представленных на сайте SpringerLink издательства Springer [12]. В том числе к английским версиям журналов "Математические заметки”, "Теоретическая и математическая физика", "Функциональный анализ и его приложения". Таким образом, сотрудники института могут читать статьи, опубликованные в этих журналах, по-английски, но при этом не могут читать те же статьи по-русски на портале Math-Net.Ru!

И если в Москве и других крупных научных центрах есть возможность найти эти журналы в библиотеках, в большинстве российских городов такой возможности нет. Интернет, в свою очередь, есть практически везде. При общем информационном голоде в настоящее время на математическую литературу нам представляется крайне необходимым сделать все возможное, чтобы доступ к системе Math-Net.Ru, как и ко всем другим подобным системам, был максимально свободным.

\footnotetext{
3 Для этих журналов подготовлены обширные электронные архивы. Скажем, для "Успехов математических наук" - за 70 лет, т. е. за все годы существования журнала; для "Математического сборника" (самого древнего российского математического журнала - он начал выходить в 1866 году!) - за 40 лет и т. д.
} 
ТАБЛИЦА 1

\begin{tabular}{|c|c|}
\hline Издание & $\begin{array}{l}\text { Уровень доступа } \\
\text { к полным текстам }\end{array}$ \\
\hline $\begin{array}{l}\text { Алгебра и логика } \\
\text { (ИМ СО РАН, Новосибирск) }\end{array}$ & $\begin{array}{l}\text { свободный доступ* по прошествии } \\
3 \text { лет с момента выхода } \\
\text { соответствующего выпуска журнала }\end{array}$ \\
\hline $\begin{array}{l}\text { Дискретная математика } \\
\text { (Наука, Москва) }\end{array}$ & доступ закрыт \\
\hline $\begin{array}{l}\text { Дискретный анализ } \\
\text { и исследование операций } \\
\text { (ИМ СО РАН, Новосибирск) }\end{array}$ & $\begin{array}{l}\text { свободный доступ* предоставляется } \\
\text { после } 1 \text { июля года, следующего } \\
\text { за годом публикации }\end{array}$ \\
\hline $\begin{array}{l}\text { Лекционные курсы НОЦ } \\
\text { (МИАН, Москва) }\end{array}$ & свободный доступ* \\
\hline $\begin{array}{l}\text { Известия Российской академии наук. } \\
\text { Серия математическая } \\
\text { (Наука, Москва) }\end{array}$ & доступ закрыт \\
\hline $\begin{array}{l}\text { Математические заметки } \\
\text { (Наука, Москва) }\end{array}$ & доступ закрыт \\
\hline $\begin{array}{l}\text { Математический сборник } \\
\text { (Наука, Москва) }\end{array}$ & доступ закрыт \\
\hline $\begin{array}{l}\text { Математическое моделирование } \\
\text { (Наука, Москва) }\end{array}$ & доступ закрыт \\
\hline $\begin{array}{l}\text { Сибирский журнал } \\
\text { индустриальной математики } \\
\text { (ИМ СО РАН, Новосибирск) }\end{array}$ & $\begin{array}{l}\text { свободный доступ* предоставляется } \\
\text { после } 1 \text { июля года, следующего } \\
\text { за годом публикации }\end{array}$ \\
\hline $\begin{array}{l}\text { Сибирский математический журнал } \\
\text { (ИМ СО РАН, Новосибирск) }\end{array}$ & $\begin{array}{l}\text { свободный доступ* предоставляется } \\
\text { после } 1 \text { июля года, следующего } \\
\text { за годом публикации }\end{array}$ \\
\hline $\begin{array}{l}\text { Современная математика. } \\
\text { Фундаментальные направления } \\
\text { (РУДН, Москва) }\end{array}$ & свободный доступ* \\
\hline $\begin{array}{l}\text { Современные проблемы математики } \\
\text { (МИАН, Москва) }\end{array}$ & свободный доступ* \\
\hline $\begin{array}{l}\text { Теоретическая и математическая } \\
\text { физика } \\
\text { (Наука, Москва) }\end{array}$ & доступ закрыт \\
\hline $\begin{array}{l}\text { Труды Математического института } \\
\text { им. В. А. Стеклова } \\
\text { (Наука, Москва) }\end{array}$ & доступ закрыт \\
\hline $\begin{array}{l}\text { Успехи математических наук } \\
\text { (Наука, Москва) }\end{array}$ & доступ закрыт \\
\hline $\begin{array}{l}\text { Фундаментальная и прикладная } \\
\text { математика } \\
\text { (МГУ, Москва) }\end{array}$ & свободный доступ* \\
\hline $\begin{array}{l}\text { Функциональный анализ и его } \\
\text { приложения } \\
\text { (Наука, Москва) }\end{array}$ & доступ закрыт \\
\hline
\end{tabular}

*Свободный доступ к полным текстам статей имеют посетители портала, прошедшие бесплатную регистрацию. 
4.2. Регистрация на портале. Любой посетитель портала может пройти бесплатную регистрацию. Заполнив несколько обязательных полей регистрационной формы ("Фамилия", "Имя", "Отчество", "Ученая степень", "Ученое звание", "Академическое звание", "Место работы/учебы" и "E-mail"), посетители портала

- получают доступ к спискам цитированной литературы всех публикаций (см. п. 2.2.3);

- получают доступ к полным текстам статей (см. п. 4.1);

- (авторы) получают доступ к полным текстам своих статей;

- имеют возможность направить рукопись статьи в редакцию журнала через "Персональный вход" на портале Math-Net.Ru, а также проследить за процессом ее продвижения в редакции (см. п. 2.6);

- могут использовать ряд дополнительных сервисов (см., например, п. 2.5).

При заполнении всех полей регистрационной формы (таких как "Ключевые слова", "Основные темы научной работы", "Основные публикации" и др.) создается персональная страница посетителя на портале Math-Net.Ru (cм. п. 2.3).

\section{5. Обзор аналогичных российских и зарубежных информационных ресурсов в области математических наук}

5.1. Сайты российских математических журналов. Многие российские журналы имеют свои собственные сайты в Интернете (см. таблицу 2). На этих сайтах есть, как правило, информация о журнале, состав редколлегии, правила для авторов и архив журнала. Архив содержит оглавления выпусков журнала за все годы его существования или за несколько последних лет. Некоторые журналы размещают в своих архивах и полные тексты статей в виде ps- и/или pdf-файлов.

Возможность поиска разного рода информации на этих сайтах обычно достаточно ограничена или вообще отсутствует. Аннотации статей набраны, как правило, либо средствами ТЕХ'а, либо средствами html. В последнем случае простые формулы также обычно набираются командами языка html, а более сложные заменены картинками. На рис. 4 приведен пример аннотации на сайте журнала "Дискретный анализ и исследование операций" и той же аннотации в виде "html с картинками" на портале Math-Net.Ru.

5.2. Информационная система MathTree. Информационная система MathTree [13] - это каталог математических Интернет-ресурсов. На сайте MathTree представлен древовидный каталог, в котором все разделы математики разбиты на семь больших ветвей - "Алгебра и логика", "Анализ", "Геометрия и топология", “Дифференциальные, интегральные и разностные уравнения", "Теория вероятностей и математическая статистика", "Математическое программирование и Computer Science", "Приложения и другое". Каждая из ветвей разделяется на несколько менее широких ветвей и т. д. На разных уровнях каталога хранятся данные, связанные с конкретным разделом математики. Некоторые ресурсы размещены непосредственно на сайте MathTree, а некоторые - в виде ссылок на внешние Интернет-ресурсы. 
ТАБЛИЦА 2

\begin{tabular}{|c|c|c|}
\hline Журнал/Сайт & Язык & $\begin{array}{l}\text { Архив } \\
\text { (Файлы статей) }\end{array}$ \\
\hline $\begin{array}{l}\text { Алгебра и анализ } \\
\text { http://www.pdmi.ras.ru/AA/ }\end{array}$ & $\begin{array}{l}\text { рус., } \\
\text { англ. }\end{array}$ & $\begin{array}{l}\text { с } 1998 \text { г. } \\
\text { (нет) }\end{array}$ \\
\hline $\begin{array}{l}\text { Алгебра и логика } \\
\text { http://math.nsc.ru/ alglog }\end{array}$ & $\begin{array}{l}\text { рус., } \\
\text { англ. }\end{array}$ & $\begin{array}{l}\text { с } 2000 \text { г. } \\
\text { (нет) }\end{array}$ \\
\hline $\begin{array}{l}\text { Вестник Московского университета } \\
\text { http://www.msu.ru/depts/MSUPubl2005/journ.html }\end{array}$ & $\begin{array}{l}\text { рус., } \\
\text { англ. }\end{array}$ & $\begin{array}{l}\text { нет } \\
(\text { нет })\end{array}$ \\
\hline $\begin{array}{l}\text { Дискретная математика } \\
\text { http://dma.mi.ras.ru/ }\end{array}$ & pyc. & $\begin{array}{l}\text { до } 2005 \text { г. } \\
\text { (нет) }\end{array}$ \\
\hline $\begin{array}{l}\text { Дискретный анализ и исследование операций } \\
\text { http://math.nsc.ru/publishing/DAOR/daor.html }\end{array}$ & pyc. & $\begin{array}{l}\text { все годы } \\
\text { (нет) }\end{array}$ \\
\hline $\begin{array}{l}\text { Известия вузов. Математика } \\
\text { http://www.ksu.ru/journals/izvuz-ru.htm }\end{array}$ & pyc. & $\begin{array}{l}\text { нет } \\
(\text { нет })\end{array}$ \\
\hline $\begin{array}{l}\text { Математическое моделирование } \\
\text { http://www.imamod.ru/magazin }\end{array}$ & pyc. & $\begin{array}{l}1998-2003 \text { гг. } \\
\text { (есть) }\end{array}$ \\
\hline $\begin{array}{l}\text { Сибирский журнал индустриальной математики } \\
\text { http://math.nsc.ru/publishing/SIBJIM/sibjim.html }\end{array}$ & pyc. & $\begin{array}{l}\text { все годы } \\
\text { (нет) }\end{array}$ \\
\hline $\begin{array}{l}\text { Сибирский математический журнал } \\
\text { http://a-server.math.nsc.ru/publishing/smz }\end{array}$ & pyc. & $\begin{array}{l}\text { с } 1993 \text { г. } \\
\text { (нет) }\end{array}$ \\
\hline $\begin{array}{l}\text { Теория вероятностей и ее применения } \\
\text { http://www.tvp.ru/ourizd/tvp_j.htm }\end{array}$ & pyc. & $\begin{array}{l}\text { 1993-2002 гг. } \\
\text { (нет) }\end{array}$ \\
\hline $\begin{array}{l}\text { Фундаментальная и прикладная математика } \\
\text { http://mech.math.msu.su/fpm }\end{array}$ & $\begin{array}{l}\text { рус., } \\
\text { англ. }\end{array}$ & $\begin{array}{l}\text { все годы } \\
\text { (есть) }\end{array}$ \\
\hline
\end{tabular}

Подробно система МathTreе описана в работе Ю. Л. Ершова, О. А. Клименко, И. И. Матвеевой и В. В. Пикалова "Математическая информационная система MathTree", которая публикуется в настоящем выпуске журнала.

5.3. Сайты зарубежных издательств. Список издательств, специализирующихся на выпуске математической литературы, приведен на портале Math-Net.Ru в рубрике "Полезные ссылки". Мы коротко остановимся на описании сайта SpringerLink издательства Springer, посредством которого распространяются, в частности, английские версии многих российских математических журналов.

Безусловным положительным моментом здесь является то, что большое количество журналов собрано в единую систему. К недостаткам можно отнести следующее:

- страницы сайта чрезмерно перегружены;

- некорректное отображение некоторых формул, встречающихся в названиях и аннотациях;

- некорректное отображение кириллических текстов.

Последний пункт проиллюстрирован на рис. 5 на примере статьи из российсковенгерского журнала "Analysis Mathematica", написанной на русском языке (cм. http: //www . springerlink. com/content/r272617556156805/).

Списки цитированной литературы на SpringerLink доступны только подписчикам. По количеству ссылок на реферативные базы данных в этих списках (см. п. 2.2.2) сайт SpringerLink, как правило, уступает порталу Math-Net.Ru. 
Л.А. Шоломов

О сложности последов ательной реализации частичных булевых функций схемами

Cтр. 110-139.

Пара $(f, g)$ частичных булевых функций характеризуется параметром $l_{\alpha \beta}-$ числом наборов $\widetilde{x}$, на которых, где $\alpha$ и $\beta$ $(f(\widetilde{x}), g(\widetilde{x}))=(\alpha, \beta)$ реализация системы $(f, g)$, когда сначала строится схема $S_{f}$ для $f$, которая затем достраивается до схемы $S_{f g}$. Показано, что если область определения $D(f)$ включает $D(g)$, то можно последовательно реализовать $f$ и $g$ так, чтобы схемы $S_{f}$ и $S_{f, g}$ были одновременно асимптотически минимальными (т. е. удовлетворяли асимптотически наилучшим оценкам сложности для соответствующих классов), и что эти функции, вообще говоря, нельзя последовательно реализовать в порядке $g, f$, чтобы асимптотически минимальными были $S_{g}$ и $S_{f, g}$. Получена достижимая нижняя оценка сложности схем $S_{f g}$ при последовательной реализации. Существенную роль играют информационные свойства частично определёных данных, изучение которых начато в предшествующих работах автора и продолжено здесь. Библ. 12.

Дискретн, анализ и исслед. опер., серия 1, 2007, 14:1,110-139

О сложности последовательной реализации частичных булевых функций схемами

Л. А. Шоломов

Институm системного анализа РАH

Пара $(f, g)$ частичных булевых функций характеризуется параметром $l_{\alpha, \beta}-$ чиспом наборов $\widetilde{x}$. на которых $(f(\widetilde{x}), g(\widetilde{x}))=(\alpha, \beta)$. где $\alpha$ и $\beta$ принимают значения 0,1 и неопределённое. Рассматривается поспедовательная реализация системы $(f, g)$, когда сначала строится схема $S_{f}$ для $f$, которая затем достраивается до схемы $S_{f, g}$ Показано, что еспи обпасть определения $D(f)$ вкпючает $D(g)$. то можно поспедовательно реализовать $f$ и $g$ так, чтобы схемы $S_{f}$ и $S_{f, g}$ были одновременно асимптотически минимальными (т.е. удовпетворяли асимптотически наилучшим оценкам спожности для соответствующих классов), и что эти фуункции, вообще говоря, нельзя поспедовательно реализовать в порядке $g, f$, чтобы асимптотически минимальными были $S_{g} и S_{f, g}$. Получена достюжимая никняя оценка сложности схем $S_{f, g}$ при поспедовательной реализации. Существенную роль играют инсформационные свойства частично определённых данных, изучение которых начато в предшествующих работах автора и продогжено здесь.

Бибп. 12

Рис. 4

Ср., например, списки цитированной литературы к одной из статей журнала "Теоретическая и математическая физика":

http://www.springerlink. com/content/p8t016v545j0816q/ (SpringerLink), http://mi.mathnet.ru/tmf/146/1/17 (Math-Net.Ru).

Нетрудно заметить, что ссылок во втором случае найдено гораздо больше.

\section{4. Реферативные базы данных.}

5.4.1. MathSciNet. Ключевым компонентом сайта Американского математического общества [14] является реферативная база данных MathSciNet [9].

MathSciNet является электронной базой данных рефератов, аннотаций и библиографической информации для большого количества литературы в области математических наук. Она содержит информацию о двух миллионах публикаций, ежегодно пополняясь на более чем 80 тысяч записей. MathSciNet является современной реализацией реферативного журнала Mathematical Reviews (MR), который начал издаваться еще в 1940 году.

На странице каждой публикации на сайте MathSciNet имеется либо реферат, написанный независимым экспертом, либо аннотация к статье, либо просто 
Ђ. П. Долж $\hbar_{\mathrm{H} \text { Ко }} 1$

(1) МБХАНИКО-МАТЬМАТИЧЂСКИЈ ФАКУ ЛЬТБТ, УН ИВ БРСИТ БТ ИМ. М. В. ЛОМОНОСОВА, МОСКО ВСК ИЈ ГОСУДАРСТВ БНН Ы Ј, 117234

Посвяпађтся П. Л. Ульянову Ћ Бг

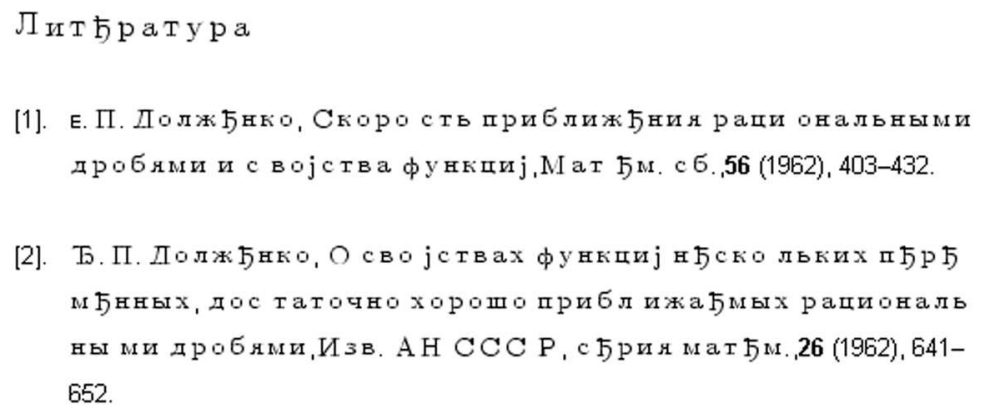

Рис. 5

цитата из самой статьи, описывающая ее содержание. Кроме того, для ряда журналов приводится список цитируемой в этой статье литературы, снабженный ссылками на соответствующие страницы этих публикаций в базе данных MathSciNet. Также можно со страницы публикации попасть на сайт соответствующего журнала или страницу этой публикации на сайте издателя, если таковые имеются.

Крайне полезной нам представляется возможность посмотреть список из десяти наиболее цитируемых работ конкретного автора - рубрика "Ссылки на Авторов".

Например, наиболее цитируемая статья А. А. Гончара (в 18 публикациях) Gonchar, A. A.; Rakhmanov, E. A. Equilibrium distributions and the rate of rational approximation of analytic functions. (Russian) Mat. Sb. (N.S.) 134(176) (1987), no. 3, 306-352, 447; translation in Math. USSR-Sb. 62 (1989), no. 2, 305-348 (MR 0922628). Всего же работы А. А. Гончара цитируются в 209 публикациях 105 авторами. Или, скажем, статьи А.Н. Колмогорова цитируются в 953 публикациях 1131 автором.

Конечно, как и на портале Math-Net.Ru, еще не все публикации, представленные в системе MathSciNet, снабжены списком цитируемой литературы (для большинства журналов они присутствуют в статьях начиная с 2000 года) и, как следствие, приведенные данные о цитируемости различных авторов пока неполные.

Также можно посмотреть и на статистику цитируемости статей из конкретного журнала (рубрика "Ссылки на Журналы"). На рис. 6 приведена диаграмма цитируемости статей журнала "Успехи математических наук" в работах, опубликованных в реферируемых MathSciNet журналах в 2006 году. 


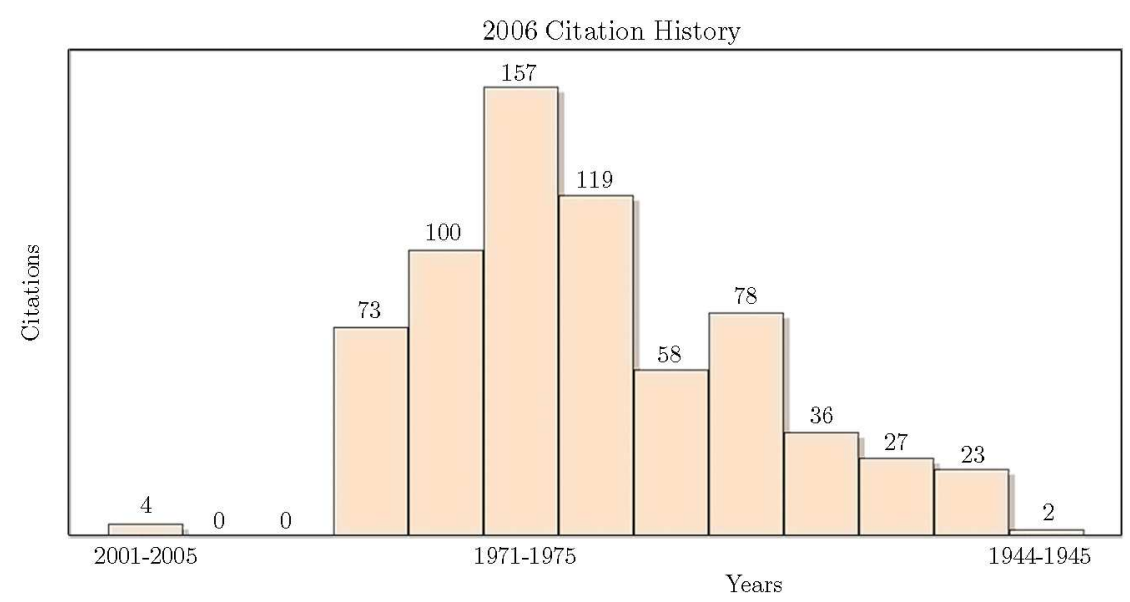

Рис. 6

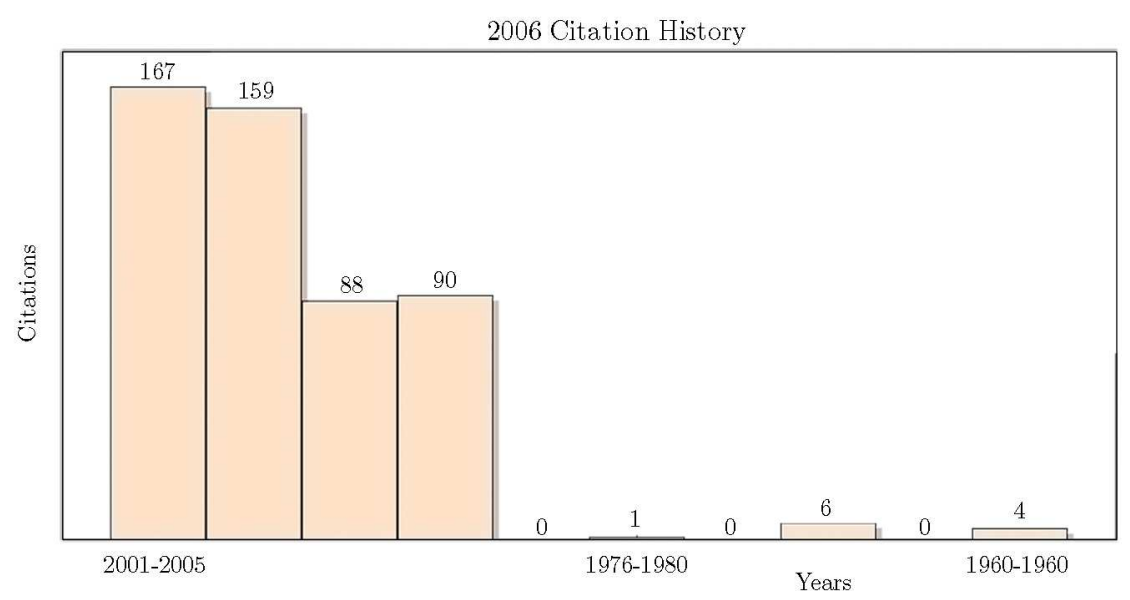

Рис. 7

Каждый столбик диаграммы показывает, сколько раз в 2006 году цитировались статьи из "Успехов", опубликованные в журнале в соответствующий период. Например, "пик" диаграммы показывает, что статьи, опубликованные в "Успехах" в 1976-1980 гг., цитировались в 2006 году в 157 публикациях. Если посмотреть на статистику 2000 года, "пик" соответствующей диаграммы также приходится на период 1976-1980 гг. и равен 180. Общее же количество публикаций, представленных в реферативной базе данных MathSciNet, цитирующих статьи из "Успехов", - 6607.

Здесь уместно отметить проблему, которая постоянно возникает при подсчете различных индексов цитирования. Как правило, при подобных подсчетах русскоязычные версии журналов и их переводные версии рассматривают как отдельные издания. Это приводит к тому, что если цитируется, скажем, статья из журнала "Russian Mathematical Surveys", это никак не влияет на индекс 
цитирования для журнала "Успехи математических наук", что, безусловно, приводит к искаженному представлению о цитируемости соответствующей работы. Так вот, если взглянуть на диаграмму для журнала "Russian Mathematical Surveys" (рис. 7) - аналогичную той, что представлена на рис. 6, - картина будет совершенно иной.

Итак, система MathSciNet является современной реферативной базой данных с большим количеством полезных сервисов. Единственной проблемой является то, что все они доступны только ее подписчикам. Пару лет тому назад Отделение математических наук при поддержке трех ведущих журналов - "Известия РАН. Серия математическая", "Математический сборник" и "Успехи математических наук" - организовало консорциум из 17 российских математических организаций, ставший подписчиком MathSciNet. Так что основные математические центры страны получили возможность пользоваться этой системой.

5.4.2. Zentralblatt MATH. Реферативная база данных Zentralblatt MATH [10] является ключевым разделом портала Европейского математического общества EMIS - The European Mathematical Information Service [15]. Она поддерживается Европейским математическим обществом, FIZ Karlsruhe и Академией наук Гейдельберга (Heidelberg Academy of Sciences and Humanities).

По своему содержанию и возможностям поиска различной информации она очень похожа на MathSciNet, поэтому мы не будем подробно описывать разнообразные аспекты ее функционирования. Отметим только, что, на наш взгляд, эта система несколько уступает своему американскому аналогу. Правда, несомненным ее преимуществом является то, что, в отличие от MathSciNet, peфераты статей доступны всем посетителям сайта, а не только подписчикам. Единственным ограничением здесь является лишь количество найденных публикаций. Для всех посетителей доступны только три найденные публикации из базы данных Zentralblatt MATH, в то время как подписчики имеют возможность получить полный список всех найденных по любому поисковому запросу статей.

\section{6. Перспективы развития портала Math-Net.Ru}

В этом разделе описан ряд направлений, по которым предполагается развивать проект Math-Net.Ru.

6.1. Подписка на текущие выпуски электронных версий изданий. В зарубежных издательствах подписка на журналы существует двух видов традиционная, на печатные выпуски журнала, и "online" подписка - на электронную версию журнала (плюс, разумеется, "комбинированная" - на обе версии одновременно). Преимущества электронной версии журнала над печатной очевидны. Это, безусловно, оперативность доступа к публикациям и огромные возможности различного рода поиска необходимой информации, зависящие, конечно, от информационной системы, используемой соответствующим издателем.

Большинство журналов не являются узкоспециализированными и публикуют в одних и тех же выпусках статьи на различные темы. Тем самым, как 
правило, для конкретного читателя интерес могут представлять лишь отдельные статьи, а не весь выпуск журнала целиком. Кроме того, информационная система, объединяющая большое количество различных изданий, имеет неоспоримое преимущество не только над набором печатных выпусков журналов, но и над сайтами отдельных журналов.

В последнее время тиражи печатных изданий неуклонно падают, а количество подписчиков на online-версии журналов - растет.

Подписка же на электронные версии российских журналов в большинстве случаев до сих пор вообще отсутствует. Ярчайший пример здесь - это Издательство "Наука" Российской академии наук, не имеющая, насколько нам известно, даже предварительных разработок, необходимых для организации соответствующей информационной системы.

Некоторые шаги в организации online-подписки предпринимает Научная электронная библиотека [16].

В такой ситуации нам представляется вполне возможным и целесообразным, чтобы российские издательства (и в первую очередь Издательство "Наука") организовали подписку на электронные версии российских математических журналов на базе портала Math-Net.Ru.

6.2. Создание реферативной базы данных. Две ведущие мировые электронные реферативные базы данных Американского математического общества MathSciNet [9] и Европейского математического общества Zentralblatt MATH [10] развились из соответствующих печатных реферативных журналов Mathematical Reviews и Zentralblatt für Mathematik. K сожалению, Всероссийский институт научной и технической информации (ВИНИТИ РАН), издающий Реферативный журнал "Математика", не имеет его электронной версии в аналогичной современной форме. При этом между ним и Отделением математических наук РАН уже давно и безуспешно ведутся переговоры об участии ВИНИТИ в проекте и размещении статей, публикуемых РЖ "Математика", на портале Math-Net.Ru.

Система Math-Net.Ru по духу и различным возможностям очень близка упомянутым реферативным базам данных. В случае достижения договоренности с ВИНИТИ о передаче подготовленных рефератов статей из российских математических журналов, база данных "ЖКурналы" на портале Math-Net.Ru могла бы превратиться в российскую реферативную базу данных в области математических наук.

6.3. Расширение списка участвующих в проекте журналов. В настоящее время в систему Math-Net.Ru вовлечены семнадцать российских математических изданий. Мы надеемся, что этот список будет постоянно расширяться. Имеются предварительные договоренности об участии журналов, издаваемых Московским государственным университетом им. М. В. Ломоносова, и Санкт-Петербургских математических журналов. Безусловно, необходимо привлекать также журналы, специализирующиеся на работах по прикладной математике и механике.

В проекте выразили желание участвовать и ряд физических журналов. Инициативу в этом направлении проявляет руководство Московского государственного университета им. М. В. Ломоносова и представители Физико-технического 
института им. А. Ф. Иоффе РАН (Санкт-Петербург). Так что, возможно, в скором будущем проект можно будет переименовать в Phys-Math-Net.Ru.

6.4. Единая база данных цитируемой литературы. Объединение списков цитированной литературы из всех публикаций в единую базу данных позволит создать еще один мощный ресурс, помогающий лучше ориентироваться в потоке научных публикаций (уже не только статей в периодических изданиях, но и книг, монографий, диссертаций, препринтов...). Каждая запись будет сопровождаться ссылками на страницу соответствующей публикации на портале Math-Net.Ru, на сайте издателя [17] и в основных реферативных базах данных [9]-[11].

6.5. Сотрудничество с ассоциацией CrossRef. Ассоциация CrossRef это международная организация, регистрирующая DOI - идентификаторы цифровых объектов (Digital Object Identifier), которые присваиваются различным электронным публикациям, в том числе статьям в журналах. В отличие от обычного сетевого адреса документа (URL), DOI присваивается "навечно" - если у статьи меняется адрес из-за реорганизации сайта, или, скажем, у соответствующего журнала меняется издатель, DOI остается неизменным.

Нам не известно ни одного российского научного издательства, которое бы начало присваивать своим публикациям DOI. Это, видимо, объясняется неразвитостью электронных версий журналов, выходящих на русском языке. При этом, как следует из нашей переписки с представителями CrossRef, нет никаких препятствий со стороны Ассоциации, мешающих российским журналам начать присваивать DOI своим публикациям.

Сотрудничество российских издательств с CrossRef, кроме получения возможности присваивать статьям уникальные идентификаторы (DOI), позволит получить различные дополнительные возможности. Например, засылая в CrossRef вместе с информацией о публикациях списки цитированной литературы, издательства смогут получать списки статей из огромного количества изданий по всему миру, цитирующих данную публикацию. По сравнению с аналогичными списками статей от Google Scholar, эти списки будут более точными.

Заметим, что издатели переводных версий подавляющего большинства российских математических журналов присваивают DOI всем статьям. Например, уже известен DOI перевода данной статьи в журнале "Russian Mathematical Surveys": 10.1070/RM2007v062n05ABEH004455.

Попасть на страницу этой статьи в Интернете можно будет, набрав в браузеpe следующий адрес: http://dx.doi.org/10.1070/RM2007v062n05ABEH004455.

$\mathrm{B}$ рамках проекта Math-Net.Ru мы постараемся всячески содействовать тому, чтобы издательства, журналы которых представлены на портале Math-Net.Ru, стали участниками этой системы.

6.6. Видеотека. Традиционно единственным способом передачи накопленных знаний и, в частности, информирования научного сообщества о полученных научных результатах была их публикация в различных печатных изданиях - книгах, журналах и т. п. С развитием Интернета появилась возможность публиковать эти самые результаты в электронном виде, как параллельно с печатными версиями, так и непосредственно на различных Интернет-сайтах - 
начиная с домашних страниц авторов и кончая такими популярными базами данных препринтов, как arXiv.org [18].

Последнее время появилась еще одна возможность передачи полученных знаний - видеозапись докладов, сделанных в ходе различных научных семинаров и конференций. Заметим, что результаты, излагаемые в устной форме, как правило, еще нигде в тот момент не опубликованы.

Приведем два примера известных нам коллекций видеоматериалов такого рода. На сайте Математического института им. В.А. Стеклова РАН [5] имеется подборка видеозаписей докладов на ежемесячном Общеинститутском семинаре "Математика и ее приложения" начиная с 2004 года. 4 Также имеются видеозаписи некоторых выступлений и докладов на конференциях и других мероприятиях, проходящих в институте.

Ha сайте Math.Ru [19], учредителями которого являются Отделение математических наук РАН [7] и Московский центр непрерывного математического образования [20], в разделе "Медиатека" размещены видеозаписи лекций, прочитанных известными учеными на Малом мехмате Московского государственного университета им. М. В. Ломоносова, а также лекции, прочитанные во время летних школ "Современная математика" [21], которые начиная с 2001 года проводят Отделение математических наук РАН, Математический институт им. В. А. Стеклова РАН, Московский комитет образования и Московский центр непрерывного математического образования.

Видеозапись, в том числе видеотрансляция в прямом эфире через Интернет, наиболее интересных выступлений известных математиков и, вообще, важнейших мероприятий, связанных с математической жизнью в стране, представляется нам крайне полезным и перспективным направлением. Это направление как один из способов распространения и хранения научной информации предполагается развивать и в рамках проекта Math-Net.Ru.

\section{Список цитируемых Интернет-ресурсов}

[1] Общероссийский математический портал Math-Net.Ru, http://www . mathnet.ru/.

[2] World Wide Web Consortium (W3C) Math Home, http://www.w3.org/Math/.

[3] $\mathrm{LT}_{\mathrm{E}} \mathrm{X} 2 \mathrm{HTML}$ developer's site, http://www . latex2html.org/.

[4] Конвертирование $\mathrm{IAT}_{\mathrm{E}} \mathrm{X}$ в html, http://wiki.botik.ru/LaTeX/LaTeX2html.

[5] Сайт Математического института им. В. А. Стеклова РАН, http://www.mi.ras.ru.

[6] Сайт Московского математического общества, http://mms . mathnet.ru/.

[7] Портал Отделения математических наук РАН, http://omn.ras.ru/.

[8] Google Scholar, http://scholar.google.com/.

\footnotetext{
${ }^{4}$ Информация о заседаниях этого семинара регулярно публикуется в журнале "Успехи математических наук" начиная с 2002 года.
} 
[9] MathSciNet - Mathematical Reviews on the Web, http://www . ams.org/mathscinet.

[10] Zentralblatt MATH - ZMATH Online Database, http://www.zentralblatt-math.org/zmath/ (основной сайт); http://emis.mi.ras.ru/ZMATH/ (российский зеркальный сайт).

[11] ADS NASA - NASA Astrophysics Data System, http://adsabs.harvard.edu/.

[12] Сайт SpringerLink издательства Springer, http://springerlink. metapress.com/.

[13] MathTree - Каталог математических Интернет-ресурсов, http://www .mathtree.ru/.

[14] American Mathematical Society, http://www . ams.org/.

[15] EMIS - The European Mathematical Information Service (supported by the European Mathematical Society), http://www.emis.de/ (основной сайт); http://emis.mi.ras.ru/ (российский зеркальный сайт).

[16] Научная электронная библиотека, http://elibrary.ru/.

[17] Crossref association, http://www. crossref .org/.

[18] База данных препринтов arXiv.org, http://arxiv.org/.

[19] Math.Ru, http://math.ru/.

[20] Московский центр непрерывного математического образования, http://www.mccme.ru/.

[21] Летняя школа "Современная математика", http://www.mccme.ru/dubna/.

\section{А. Б. Жижченко (А. В. Zhizhchenko)}

Поступила в редакцию Математический институт им. В. А. Стеклова РАН

E-mail: om@ras.ru

\section{А. Д. Изаак (A. D. Izaak)}

Математический институт им. В. А. Стеклова РАН

E-mail: izaak@mi.ras.ru 